Inquiry

An Interdisciplinary Journal of Philosophy

ISSN: 0020-174X (Print) 1502-3923 (Online) Journal homepage: https://www.tandfonline.com/loi/sinq20

\title{
Moral realism and semantic accounts of moral vagueness
}

\section{Ali Abasnezhad}

To cite this article: Ali Abasnezhad (2019): Moral realism and semantic accounts of moral vagueness, Inquiry, DOI: 10.1080/0020174X.2019.1570866

To link to this article: https://doi.org/10.1080/0020174X.2019.1570866

\section{曲 Published online: 28 Jan 2019.}

$\sqrt{6}$ Submit your article to this journal $\square$

Џll Article views: 98

Q View related articles $\sqsubset$

View Crossmark data ¿ 


\title{
Moral realism and semantic accounts of moral vagueness
}

\author{
Ali Abasnezhad \\ Munich Center for Mathematical Philosophy, LMU Munich, Munich, Germany
}

\begin{abstract}
Miriam Schoenfield argues that moral realism and moral vagueness imply ontic vagueness. In particular, she argues that neither shifty nor rigid semantic accounts of vagueness can provide a satisfactory explanation of moral vagueness for moral realists. This paper constitutes a response. I argue that Schoenfield's argument against the shifty semantic account presupposes that moral indeterminacies can, in fact, be resolved determinately by crunching through linguistic data. I provide different reasons for rejecting this assumption. Furthermore, I argue that Schoenfield's rejection of the rigid semantic account is based on a presupposition that ultimately implies the very same claim that is under dispute: the vagueness of moral predicates in imperfect languages persists in the perfect language, as well.
\end{abstract}

ARTICLE HISTORY Received 7 July 2018; Accepted 14 December 2018

KEYWORDS Moral realism; moral vagueness; ontic vagueness; semantic accounts of vagueness; epistemicism; moral indeterminacy

\section{Introduction}

The usual presentations of vagueness involve cases that may seem unimportant. For instance, the fact that it is indeterminate whether a person with the height of $177 \mathrm{~cm}$ is tall does not seem to crucially affect our everyday life. Nor the intuition that one hair difference does not change whether someone is bald, which leads to contradiction, seems to be important. ${ }^{1}$ However, vagueness also appears in much more significant situations, such as moral permissibility (e.g. it is indeterminate whether

CONTACT Ali Abasnezhad abasnejad.ali@gmail.com Munich Center for Mathematical Philosophy, Ludwig Maximilian University of Munich, Ludwigstr. 31/II, 80539 Munich, Germany

${ }^{1}$ This is called tolerance intuition, which traces back to (Wright 1975, 1976). In general, three main features are associated to phenomena of vagueness: borderline cases, blurry boundaries and tolerance. See Keefe (2000) and Williamson (1994) for discussion.

(c) 2019 Informa UK Limited, trading as Taylor \& Francis Group 
an abortion at 19 weeks is morally permissible), where the indecisiveness crucially can affect one's life. ${ }^{2}$

One would think that the standard explanations of vagueness, such as semantic and epistemic explanations, should also be applicable to moral vagueness. ${ }^{3}$ On the other hand, it may seem that whether the standard solutions to vagueness could be applied to moral vagueness depends on one's view of morality. Nonetheless, the main proponents of the standard views of vagueness, such as David Lewis and Timothy Williamson, are realist, so at least moral realists should not have any problem with the standard explanations to moral vagueness, one would think. ${ }^{4}$ However, in her recent paper, 'Moral Vagueness Is Ontic Vagueness', Miriam Schoenfield argues against the consistency of semantic explanation of moral vagueness and moral realism. She considers two semantic explanations, shifty and rigid, and argues that neither can explain moral vagueness for moral realists. In particular, she argues that the shifty semantic account fails to make sense of moral deliberation (S-objection), and the rigid view ultimately leads to ontic vagueness (R-objection).

In this paper, I aim to defend the consistency of semantic explanations of moral vagueness with moral realism from Schoenfield's objection. ${ }^{5}$ Specifically, I argue that both rigid and shifty semantic accounts of vagueness can explain moral vagueness for moral realists. I explain that Schoenfield's argument against the shifty semantic view rests on a presupposition that neither proponents of the shifty semantic view are committed to accept, nor is it generally reasonable to accept. Furthermore, I show that Schoenfield's argument against the rigid semantic view is not sound. In order for the argument to be sound, she has to assume a premise that implies the very same claim that is under dispute, i.e. the vagueness of moral predicates in imperfect languages persists in the perfect language.

Before going further, however, let us agree on the following definitions, which we need in the rest of this paper.

Moral Realism (MR): Moral properties are part of the deep underlying metaphysical structure of the world and they are obtained entirely independently of how we conceptualize the world. Furthermore, moral truths are necessary. ${ }^{6}$

\footnotetext{
${ }^{2}$ See Shafer-Landau (1995) for earlier discussion on moral realism and vagueness. Also, see Dougherty (2017) and Schoenfield (2016, 262-3) for more examples of vagueness in moral issues.

${ }^{3}$ Moral vagueness' simply refers to the vagueness of moral terms, in particular moral predicates.

${ }^{4}$ See Lewis (1982) and Williamson (1994) for semantic and epistemic accounts of vagueness, respectively.

${ }^{5}$ However, as we shall see later, my defense of the semantic view ultimately undermines Schoenfield's main objection to Williamson's epistemic account. Thus, at least a Williamsonian epistemicism can consistently explain moral vagueness for moral realists.

${ }^{6}$ See Dougherty (2014, 352-72 and 358).
} 
Furthermore, ontic vagueness can be characterised as:

Ontic Vagueness (OV): The kind of vagueness that would remain even if we spoke a perfect language and were omniscient, where a perfect language is a language that contains all and only predicates that are necessary to provide a complete and accurate description of how things are fundamentally.

According to the semantic view of vagueness, vagueness is a feature of our language, in the sense that vague predicates lack precise application conditions. This is because the reference-fixing facts are not able to fully determine the extensions of vague predicates. In other words, among several possible extensions for a vague predicate, it is indeterminate which one is the extension of the vague predicate. ${ }^{8}$

Following these definitions, moral realists should think that a perfect language contains predicates that refer to moral properties/relations (otherwise, a complete and accurate description of how things are fundamentally would not tell us how things are morally). Accordingly, moral realists who accept the semantic view of moral vagueness think that in a perfect language, moral predicates would have precise application conditions.

\section{Shifty semantic account of vagueness}

Let us call a semantic account of vagueness shifty if it implies that a slight change of application of predicate ' $\boldsymbol{P}$ ' could change its referent (extension), and so the truth value of the sentences ' $\mathbf{P a}^{\prime}$. ${ }^{9}$ Call a semantic account rigid if it implies that a slight change of application of ' $\boldsymbol{P}$ ' does not change its refer-

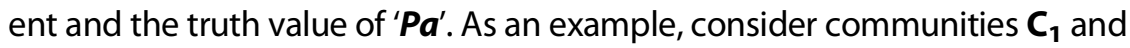
$\mathbf{C}_{\mathbf{2}}$ that are similar in all respects except $\boldsymbol{a}$ is $\boldsymbol{P}$ in $\mathbf{C}_{\mathbf{1}}$ but not in $\mathbf{C}_{\mathbf{2}}$. According to the shifty view, ' $\mathbf{P a}$ ' is true in $\mathbf{C}_{\mathbf{1}}$ and false in $\mathbf{C}_{\mathbf{2}}$, since the truth value of ' $\boldsymbol{P a}$ ' is sensitive to how predicate ' $\boldsymbol{P a}$ ' is used in a community. However, according to the rigid view, ' $\mathbf{P a}$ ' has the same truth value in $\mathbf{C}_{\mathbf{1}}$ and $\mathbf{C}_{\mathbf{2}}{ }^{10}$

Schoenfield argues that the shifty semantic account cannot make sense of moral deliberation for moral realism. To see this, suppose Cheryl feels conflicted about whether $\boldsymbol{a}$ is $\boldsymbol{P} .{ }^{11}$ She then gets provided with some

\footnotetext{
${ }^{7}$ See Barnes (2014, 339-62 and 339). Also, see Abasnezhad and Jenkins (2018) for a recent discussion of Barnes' theory of ontic vagueness and Abasnezhad and Hosseini (2014) for an alternative theory of ontic vagueness.

${ }^{8}$ See Fine (1975), Lewis (1986) and Keefe (2000).

${ }^{9}$ Here ' $\boldsymbol{P}$ ' stands for a vague moral predicate, which has some clear cases of positive/negative application and some borderline cases for which it is indeterminate whether $\boldsymbol{P}$. We can think that ' $\boldsymbol{P}$ ' refers to 'is morally permissible'. Furthermore, 'application of predicate' means its linguistic usage here.

${ }^{10}$ Informally, according to the shifty view, the truth value of 'John is tall' depends to the way 'tall' is used in a community, and hence the truth value may change from one community to the other. According to the rigid view, however, the truth value does not change from one community to the other.

${ }^{11}$ For instance, whether an abortion at 19 weeks is morally permissible.
} 
linguistic data from a series of surveys about the way language users in her community use ' $\boldsymbol{P}$ '. Schoenfield thinks that the shifty semantic account implies that Cheryl is now in a position to decide whether $\boldsymbol{a}$ is $\boldsymbol{P}$. She finds this problematic for moral realists since it implies that crunching through linguistic data is a way of resolving doubts about whether $\boldsymbol{a}$ is $\boldsymbol{P}$, which is not acceptable for moral realists. ${ }^{12}$ Hence, Schoenfield rejects the shifty semantic account of moral vagueness for moral realists.

In the rest of this section, I argue that Schoenfield's argument is not valid. In particular, I explain that committing to the shifty sematic view does not imply that the indeterminacy in whether $\boldsymbol{a}$ is $\boldsymbol{P}$ can be resolved by crunching through linguistic data.

\subsection{Against S-objection}

Schoenfield's argument rests on an ungrounded assumption:

I) Accepting the shifty semantic view implies that in cases like whether $\boldsymbol{a}$ is $\boldsymbol{P}$, about which Cheryl is uncertain, she can find out that in fact, determinately $\boldsymbol{a}$ is $\boldsymbol{P}$ (or is not $\boldsymbol{P}$ ) by collecting linguistic data. ${ }^{13}$

Schoenfield neither provides an argument for (I), nor does it seem to be straightforward. I argue that (I) is not a reasonable assumption and proponents of the shifty semantic account of vagueness cannot accept it. In particular, I explain that it is not generally the case that the knowledge of linguistic data concerning $\mathbf{P a}$ yields to the knowledge that determinately $\mathbf{P a}($ not $\mathbf{P a})$, when it is indeterminate whether $\mathbf{P a}$.

Suppose Cheryl is a competent speaker in her linguistic community. This means that she can determine whether $\boldsymbol{a}$ is $\boldsymbol{P}$, if $\boldsymbol{a}$ is a clear case of $\boldsymbol{P}$. So, if Cheryl is puzzled whether $\boldsymbol{a}$ is $\boldsymbol{P}, \boldsymbol{a}$ should be a borderline case of $\boldsymbol{P} .{ }^{14}$ Now, the question is: if $\boldsymbol{a}$ is a borderline case of $\boldsymbol{P}$, can it be determined whether $\boldsymbol{a}$ is $\boldsymbol{P}$ by collecting linguistic data? Contrary to Schoenfield's assumption, I argue it cannot be determined. The assumption that one can resolve whether $\boldsymbol{a}$ is $\boldsymbol{P}$ by gathering linguistic data, even if $\boldsymbol{a}$ is a borderline case

\footnotetext{
${ }^{12}$ More precisely, Schoenfield thinks that it is unacceptable for moral realists to say that Cheryl can find out, for instance, whether some abortion, for which she was initially uncertain, is in fact determinately permissible by collecting linguistic data; Schoenfield $(2016,266)$.

${ }^{13}$ Schoenfield $(2016,266)$.

${ }^{14}$ This seems to be a reasonable requirement for being a competent speaker. If someone feels conflicted about whether a person with the height of $195 \mathrm{~cm}$ is tall (or a person with the height $160 \mathrm{~cm}$ is non-tall) in our normal community, then she does not seem to be a competent English speaker. Alternatively, one could appeal to a theory that suggests most people are mistaken about moral facts while competent about the usual practice of how moral terms are used. However, appealing to such a theory will undermine the idea that collecting linguistic data are helpful in resolving moral indeterminacies. I am grateful to the referee for pointing this out.
} 
of $\boldsymbol{P}$, seems to be based on a misconception of borderline cases. $\boldsymbol{a}$ being a borderline case of $\boldsymbol{P}$ is not a result of insufficient linguistic data. Rather, it is because the linguistic rules governing the application of $\boldsymbol{P}$ are unable to decide whether $\boldsymbol{a}$ is $\boldsymbol{P} .^{15}$ Hence, if in a community, it is indeterminate whether $\boldsymbol{a}$ is $\boldsymbol{P}$ (due to $\boldsymbol{a}$ being a borderline case of $\boldsymbol{P}$ ), collecting linguistic data from the community cannot help decide whether $\boldsymbol{a}$ is $\boldsymbol{P}$.

To demonstrate this, consider a situation where Cheryl is provided with a collection of data from the community about $\boldsymbol{a}$ being $\boldsymbol{P}$. Suppose the data is the result of surveys in which people asked about whether $\boldsymbol{a}$ is $\boldsymbol{P}$ with three options: yes, no, indeterminate. Given $\boldsymbol{a}$ is a borderline case of $\boldsymbol{P}$, it would be natural to think that most people would choose the option 'indeterminate'. ${ }^{16}$ That is, going through the linguistic data doesn't necessarily resolve borderline cases, it simply reports that they are borderline cases.

Alternatively, the linguistic data could be the result of surveys in which people only have two options: yes and no. This version is not helpful to Cheryl, either. When $\boldsymbol{a}$ is a borderline case of $\boldsymbol{P}$, the linguistic rules governing application of $\boldsymbol{P}$ are not able to settle on options yes/no. That is, the responses in the survey would be arbitrary, not the result of following the rules governing the application of $\boldsymbol{P}$. This means, the difference in the number of people who choose one option over the other would be very small, which cannot help Cheryl to decide on whether $\boldsymbol{a}$ is $\boldsymbol{P}$. For example, the result of surveys of one million people in which only ten more people choose 'yes' over 'no' does not seem to be helpful in resolving Cheryl's doubts regarding whether $\boldsymbol{a}$ is $\boldsymbol{P}$. $^{17}$

Indeed, committing to the shifty semantic account does not force one to agree that the indeterminacy of borderline cases can be settled by gathering linguistic data. ${ }^{18}$ The shifty semantic account is only committed to the idea that extensions of predicates are sensitive to their linguistic usage in a community, but it does not follow that extensions of predicates are fully determinable within each community. That is, the shifty semantic

\footnotetext{
${ }^{15}$ Indeed, gathering any kind of data does not seem to help settle borderline cases. If John is a borderline case of tallness, even finding out that John's height is $177.65746 \mathrm{~cm}$ does not help to settle whether John is tall.

${ }^{16}$ Otherwise, if most people choose, for instance, 'yes', then it shows that rules governing the application of $\boldsymbol{P}$ in this community is determined about whether $\boldsymbol{a}$ is $\boldsymbol{P}$ and it is Cheryl who is not competent enough regarding how the language works.

${ }^{17}$ In fact, deciding on whether $\boldsymbol{a}$ is $\boldsymbol{P}$ based on the linguistic data, itself, seems to be subject to vagueness. In particular, it is indeterminate what the minimum amount of margin between two options should be, in order to suffice determinately choosing one option over the other.

${ }^{18}$ In fact, if the problem of borderline cases could be settled in this way, vagueness would not be such a challenging issue.
} 
account does not imply that the linguistic usage of predicate $\boldsymbol{P}$ is fully determinable by crunching through linguistic data.

Furthermore, other serious issues lie in the idea that by going through linguistic data, one can fully determine the linguistic usage of a predicate, even for borderline cases. First, note that the idea leads to the absurd consequence that the linguistic usage of a term in a community can change by change in the population size of the community. For instance, suppose according to the results of a survey about whether $\boldsymbol{a}$ is $\boldsymbol{P}, \mathrm{M}+80$ people choose 'yes' and M people choose 'no'. Suppose based on this result, Cheryl comes to the conclusion that $\boldsymbol{a}$ is $\boldsymbol{P}$. However, on the next day, 200 people who have chosen the 'yes' die in a plane crash. Now, according to the above idea Cheryl has to change her belief to $\boldsymbol{a}$ is not $\boldsymbol{P}$, since the linguistic usage of $\boldsymbol{P}$, which is determined based on the new linguistic data, implies that $\boldsymbol{P}$ does not apply to $\boldsymbol{a}$ (after the plane crash). But this is absurd. The linguistic usage of $\boldsymbol{P}$ cannot change just by change in the population size. What Schoenfield misses is the point that the linguistic usage of a predicate crucially depends on the way the predicate has been used in the community throughout the history of that community, and this is something that cannot be found out simply by gathering linguistic data. Cheryl, who is supposed to be a philosopher according to Schoenfield, should know this well. ${ }^{19}$

Finally, the idea that the knowledge of linguistic data concerning $\mathbf{P a}$ does yield knowledge that determinately $\mathbf{P a}(\sim \mathbf{P a})$, when it is indeterminate whether $\boldsymbol{P a}$, dismisses the difference between what people think of a term and how they use the term. In particular, learning how people use the term ' $\boldsymbol{P}$ ' will not always settle whether a particular case is $\boldsymbol{P}$. If you ask people whether $\boldsymbol{P a}$, what they say will be determined by: (i) what $\mathbf{P a}$ means to them; and (ii) what they believe to be true regarding $\mathbf{P a}$. For instance, if someone says that Pluto is a planet, this could be because they wrongly understand 'planet' as we did twenty years ago, and they believe rightly that Pluto is a planet according to that definition, or they understand 'planet' rightly, i.e. as we do now, but they believe wrongly that Pluto is a planet according to that definition. ${ }^{20}$ Hence, gathering such linguistic data will not necessarily determine the meaning of $\boldsymbol{P}$.

\footnotetext{
${ }^{19}$ Generally speaking, the linguistic data regarding a predicate does not always confirm linguistic usage of the predicate. While the linguistic data is the result of surveys at a certain point in time, the linguistic usage of the predicate is about the general and unwritten rules of application of the predicate over a long period.

${ }^{20}$ We now know that Pluto is not actually a planet.
} 
Indeed, linguistic data will only provide one with what people believe to be the extension of a predicate but not what the extension of the predicate actually is. ${ }^{21}$

To sum up, Schoenfield's argument that the shifty semantic account of moral vagueness cannot make sense of moral deliberation is not valid since if it is indeterminate whether $\boldsymbol{a}$ is $\boldsymbol{P}$, even by crunching through linguistic data, the indeterminacy does not resolve. ${ }^{22,23}$

\section{Rigid semantic account of vagueness}

Alternatively, a semantic account of moral vagueness might understand vague moral predicates as rigid terms. According to the rigid semantic account, the referent of predicate $\boldsymbol{P}$ does not change with small changes in its usage. However, most vague predicates seem to be shifty in the sense that they would have different extensions in communities that use them slightly differently. Therefore, moral realists who appeal to the rigid semantic account to explain moral vagueness have to explain why vague moral predicates are different. Schoenfield considers two such explanations: reference magnetism ${ }^{24}$ and conceptual role semantic theory, $^{25}$ and claims that neither can successfully explain the rigidity of vague moral predicates for moral realists.

In regards to the reference magnetism, she argues that depending on whether one accepts that the linguistic usage of a community can narrow down the class of precisifications of vague moral predicates, the theory either turns to the shifty view or it will be committed to ontic vagueness. If one agrees that the class of precisifications of $\boldsymbol{P}$ can be narrowed down by the linguistic usage of a community, then the view turns to the shifty view. Schoenfield then rejects this version of reference magnetism because of her argument against the shifty view mentioned in the previous section. Alternatively, if one rejects

\footnotetext{
${ }^{21}$ For detailed discussion on indeterminacy of meaning, see Davidson (2001), in particular 'The Inscrutability of Reference' and 'On the Very Idea of a Conceptual Scheme'.

${ }^{22}$ I should emphasize that, here, I only aimed to show that Schoenfield's argument against the shifty semantics is unsuccessful. Providing a comprehensive shifty semantic account of moral vagueness that can explain moral deliberation for moral realists is another matter and subject to another paper. I am grateful to the referee for pressing on this.

${ }^{23}$ As mentioned earlier, rejecting Schoenfield's argument against shifty semantic account results her argument against epistemic account of moral vagueness to fail too. In particular, she argues that Williamson's epistemicism cannot explain moral vagueness for moral realists since it would imply commitment to shifty semantic account. Now that it has been demonstrated that it is not a problem for moral realists to accept the shifty semantics, it should not be a problem to accept Williamson's epistemicism, either.

${ }^{24}$ See Lewis (1983).

${ }^{25}$ See Wedgwood (2001).
} 
that the linguistic usage of a community can narrow down the class of precisifications of $\boldsymbol{P}$, the view will be committed to ontic vagueness, which is clearly not acceptable for a semantic account of vagueness. $^{26}$

As shown in the last section, Schoenfield's argument against the shifty semantic account is not valid. Consequently, a reference magnetism account, that grants the linguistic usage of a community can narrow down the class of precisifications of a vague moral predicate, is not problematic, as far as its commitment to the shifty semantic account is concerned. However, one might still find this version of reference magnetism unsatisfactory due to its commitment to the shifty semantics; after all, the account was supposed to provide an explanation of the rigidity of vague moral predicates. So at least we can say that this version of reference magnetism fails to explain the rigidity of vague moral predicates.

Schoenfield's main argument against the rigid semantic account of vagueness is directed toward the conceptual role semantics, henceforth CRS. According to this view, a predicate names whatever property/relation that is best suited to play a certain conceptual role. For instance, the predicate 'better than' refers to whatever relation that makes certain rules of inference valid. ${ }^{27}$ In particular, the referent of 'better than' is a possibly vague four-place relation of the form: $\boldsymbol{x}$ is, all things considered, a better thing than $\boldsymbol{y}$ for $\boldsymbol{z}$ to do at $\boldsymbol{t}$. Furthermore, this relation makes the inference from accepting the sentence 'it is better for me to do $\boldsymbol{x}$ than $\boldsymbol{y}$ at $\boldsymbol{t}^{\prime}$ to forming the preference for doing $\boldsymbol{x}$ over $\boldsymbol{y}$ at $\boldsymbol{t}$, valid. ${ }^{28}$ The rules of inference are those of practical reason, in which sometimes the outputs are preferences, rather than beliefs. Accordingly, the notion of validity is the notion of correctness preservation. ${ }^{29}$

Schoenfield argues that if there is any semantic indeterminacy about which of a pair of actions is to be preferred, it is either because: it is indeterminate which inference rules of practical reason constitute the conceptual role for 'better than'; or it is indeterminate which relation makes the inference rules for practical reason valid. She rejects the first option since such indeterminacy will not explain the indeterminacy that arises from the sorites series. Otherwise, it would follow that fixing the rules would fix which precise relation is the referent of 'better than', which is

\footnotetext{
${ }^{26}$ See Schoenfield $(2016,270-1)$ for details.

${ }^{27}$ Following Schoenfield, I shift the focus from 'permissible' to 'better than', simply because Wedgwood uses 'better than' in developing CRS.

${ }^{28}$ See Wedgwood $(2001,18)$.

${ }^{29}$ Having a correct preference means having a preference that is permitted by the goals of practical reason.
} 
implausible. Fixing the rules of practical reason that define the conceptual role for 'better than' cannot determine a cut-off in the sorites series. ${ }^{30}$

Schoenfield finds the second option (i.e. the indeterminacy in the referent of moral terms are a result of the indeterminacy about which relations make the inference rules for practical reason valid) more promising. ${ }^{31}$ However, she claims that it leads to ontic vagueness. She argues for the two following premises, from which she concludes the account is not purely semantic. Rather, there is ontic vagueness.

A) A robust moral realist who accepts CRS should think that a perfect language will contain predicates that refer to those properties/ relations that make the inference rules for practical reason valid.

B) If it is indeterminate which properties and relations make the inference rules for practical reason valid, and a perfect language contains predicates that refer to such properties/relations, then, the perfect language will contain predicates that lack precise application conditions. $^{32}$

According to Schoenfield, A is true because a perfect language contains all and only predicates that are necessary to give a complete and accurate description of how things are fundamentally, and moral realists think that a perfect language contains predicates that refer to moral properties/ relations. Thus, moral realists who accept CRS should think that a perfect language will contain predicates that refer to those properties/ relations, which make certain rules of practical reason valid. ${ }^{33}$

Furthermore, B is true. Suppose a language contains predicates that refer to the properties/relations which make certain rules of practical reason (call them $\mathbf{R}$ ) valid. Nonetheless, it is indeterminate which properties/relations these are. If the predicates referred to properties/relations with precise application conditions, it would follow from CRS that these precise properties/relations make $\mathbf{R}$ valid. This is inconsistent with the

\footnotetext{
${ }^{30} \mathrm{Here}$, I agree with Schoenfield, so I will not go through of the details of the argument. See Schoenfield $(2016,272-3)$.

${ }^{31}$ Schoenfield does not consider a third option, where the intermediacy in vague moral terms is the result of both the indeterminacy in which inference rules of practical reason constitute the conceptual role for 'better than' and also the indeterminacy about which relations make the inference rules of practical reason valid. In particular, it could be the case that among rules $\mathbf{r}_{\mathbf{1}}, \ldots, \mathbf{r}_{\mathbf{n}}$, it is indeterminate which one constitutes the conceptual role for 'better than'. Also for each $\mathbf{r}_{\mathbf{i}}$, there are relation $\mathbf{s}_{\mathbf{1}}^{\mathbf{i}}, \ldots, \mathbf{s}_{\mathbf{m}}^{\mathbf{i}}$ such that it is indeterminate which one makes $\mathbf{r}_{\mathbf{i}}$ valid.

${ }^{32}$ Schoenfield $(2016,273)$.

${ }^{33}$ This is because according to CRS, the moral properties/relations are identical to the properties/relations that make certain rules of practical reason valid.
} 
claim that it is indeterminate which properties/relations make $\mathbf{R}$ valid. Consequently, these predicates will lack precise application conditions.

From A and B Schoenfield concludes that moral vagueness is ontic. Since, if moral predicates refer to the properties/relations that make $\mathbf{R}$ valid, and these properties/relations are indeterminate, then, even in a perfect language, moral predicates will not have precise application conditions. And if in a perfect language, moral predicates do not have precise application conditions, then moral vagueness will exist even amongst those who are omniscient and competent speakers of a perfect language.

\subsection{Against R-objection}

So far, I have argued against Schoenfield's criticism of reference magnetism concerning its commitment to the shifty semantics. I have shown that her objection against shifty semantic is not valid. In the rest of this section, I argue that Schoenfield's argument against CRS explanation of the rigidity of moral terms fails as well. First, I show that Schoenfield's argument is not sound (B is false, given the semantic account of vagueness), then I show how CRS can explain both vagueness and rigidity of moral terms for moral realists without committing to ontic vagueness.

Note that premise $\mathbf{B}$ is a conditional with a conjunction as antecedent. The first conjunct (i.e. it is indeterminate which properties/relations make the inference rules for practical reason valid) is true, given moral vagueness and CRS. The second conjunct (i.e. a perfect language contains predicates that refer to such properties/relations) is true, as well. ${ }^{34}$ However, the consequent (i.e. the perfect language will contain predicates that lack precise application conditions.) does not follow from the antecedent. This is because we are only sure that the indeterminacy in the first conjunct exists in the imperfect language. The second conjunct only states that the prefect language contains predicates that refer to such properties/relations. There is no reason to think that the reference relations in the perfect language are indeterminate, as well. On the contrary, given the nature of the perfect language, we should think that reference relations are determinate. $^{35}$ In order for $\mathbf{B}$ to be valid, Schoenfield has to assume that

\footnotetext{
${ }^{34}$ Note that the second conjunct is simply reiteration of $\mathbf{A}$, given moral realism and CRS.

${ }^{35}$ It is easier to see the falsity of $\mathbf{B}$, given the semantic account of vagueness, when reiteration of $\mathbf{A}$ in $\mathbf{B}$ is removed:

$\mathbf{B}^{\prime}$ ) If it is indeterminate which properties and relations make the inference rules for practical reason valid, then the perfect language will contain predicates that lack precise application conditions.
} 
Assumption: If there is a referential indeterminacy in the imperfect language, the indeterminacy persists in the perfect language.

However, such an assumption is obviously not permissible; it is the very same claim that is under dispute. Proponents of ontic vagueness think the assumption is true but opponents of ontic vagueness think it is false. Thus, such an assumption is nothing but presupposing the ontic vagueness, which is not permissible when one aims to argue for ontic vagueness.

So far, it is shown that Schoenfield's argument against CRS explanation is unsound. Now, let us see how CRS can actually explain both vagueness and rigidity of moral predicates for moral realists without committing to ontic vagueness. Consider the predicate 'better than' in the imperfect language of English. This predicate is vague, in particular because it accepts borderline cases. ${ }^{36}$ CRS can explain the rigidity of 'better than' by associating it to the conceptual role 'making $\mathbf{R}$ valid'. ${ }^{37}$ According to CRS, 'better than' is rigid because the slight change in the application of 'better than' does not change the conceptual role associated to the predicate. ${ }^{38}$

Now, we can provide a semantic explanation of the vagueness of 'better than' in the imperfect language without committing to vagueness in the perfect language. The predicate 'better than' is referentially indeterminate between precise relations $\mathbf{S}_{\mathbf{1}}, \ldots, \mathbf{S}_{\mathbf{n}}$, which are equally suitable in satisfying the conceptual role 'making $\mathbf{R}$ valid'. ${ }^{39}$ The referential indeterminacy is due to the lack of precise application conditions for 'better than' in the imperfect language English, not the vagueness of the relations. However, in a perfect language 'better than' does have precise application condition. As a result, omniscient and competent speakers of a perfect language are able to determinately refer to the referent of 'better than', say $\mathbf{S}_{\mathbf{i}}{ }^{40}$ There is no part in Schoenfield's argument that can block such semantic explanation of moral vagueness for moral realists.

Granting that the vagueness of imperfect language remain in the prefect language is nothing but presupposing the ontic vagueness.

${ }^{36}$ While it is the case that amputating a person's arm to save a billion lives is better than not doing the amputation and letting a billion people die and that amputating a person's arm to save another's life is not better than not doing the amputation and letting the person die, it is indeterminate whether amputating a person's arm to save hundred lives is better than not doing the amputation and letting hundred people die.

${ }^{37}$ Here, $\mathbf{R}$ is the inference from 'it is better for me to do $\boldsymbol{x}$ than $\boldsymbol{y}$ at $\boldsymbol{t}$ ' to forming the preference for doing $\boldsymbol{x}$ over $\boldsymbol{y}$ at $\boldsymbol{t}$.

${ }^{38} \mathrm{By}$ 'slight change', I mean a change from 'indeterminacy' to positive (or negative) classification. Alternatively, classifying a positive case as a negative case seems to be a major change.

${ }^{39} \mathbf{S}_{\mathbf{1}} \ldots \mathbf{S}_{\mathbf{n}}$ agree on all positive and negative cases of 'better than' and only disagree on its borderline cases.

${ }^{40}$ Such explanation makes the antecedent of $\mathbf{B}$ true and its consequent false. 
In sum, a rigid semantic account of vagueness also can explain the vagueness of moral terms without committing to ontic vagueness. In particular, CRS is a viable theory for explaining both vagueness and rigidity of moral predicates for moral realists.

\section{Conclusion}

To conclude, it has been shown that both shifty and rigid semantic accounts of vagueness can successfully explain moral vagueness for moral realists without committing to ontic vagueness. In particular, Schoenfield's argument against the shifty semantics fails because the shifty semantic account does not imply that moral indeterminacies can be resolved by crunching through linguistic data. In cases where $\boldsymbol{a}$ is a borderline case of $\boldsymbol{P}$, the result of linguistic data either just confirms that $\boldsymbol{a}$ is a borderline case of $\boldsymbol{P}$, or cannot contribute to settling whether $\boldsymbol{a}$ is $\boldsymbol{P}$. Furthermore, assuming that moral indeterminacies can be resolved by crunching through linguistic data entails the absurd conclusion that the linguistic usage of a term in a community can change by change in the population size of the community. Finally, the assumption dismisses the difference between what people think of a term and how they use the term.

Moreover, moral realists can also appeal to the rigid semantic account of vagueness to explain vagueness of moral terms without committing to ontic vagueness. Contrary to what Schoenfield argues, appealing to CRS for explaining the rigidity of vague moral predicates does not commit moral realists to ontic vagueness. Her argument is based on the assumption that the referential indeterminacy of moral predicates in imperfect languages remains in the perfect language, which ultimately leads to the very same claim that is under dispute: the vagueness moral terms in the imperfect languages remains even in the perfect language.

\section{Acknowledgements}

I am grateful to Hannes Leitgeb for discussion and comments and to the anonymous referee for very helpful comments. This work was supported by the H2020 Marie Skłodowska-Curie Actions [grant agreement number 675415].

\section{Disclosure statement}

No potential conflict of interest was reported by the author. 


\section{Funding}

This work was supported by the H2020 Marie Skłodowska-Curie Actions [grant agreement number 675415].

\section{References}

Abasnezhad, A., and D. Hosseini. 2014. "Vagueness in the World: A Supervaluationist Approach." In Vague Objects and Vague Identity, edited by K. Akiba, and A. Abasnezhad, 239-256. Dordrecht: Springer.

Abasnezhad, A., and C. Jenkins. 2018. "Metaphysical Vagueness Without Vague Objects." Thought: A Journal of Philosophy 7 (4): 278-283.

Barnes, E. 2014. "Fundamental Indeterminacy." Analytic Philosophy 55: 339-362.

Davidson, D. 2001. Inquiries into Truth and Interpretation. Oxford: Clarendon Press.

Dougherty, T. 2014. "Vague Value." Philosophy and Phenomenological Research 89: 352-372.

Dougherty, T. 2017. "Vagueness and Indeterminacy in Metaethics." In The Routledge Handbook of Metaethics, edited by Tristram McPherson and David Plunkett, 185193. London: Routledge.

Fine, K. 1975. "Vagueness, Truth and Logic." Synthese 54: 235-259.

Keefe, R. 2000. Theories of Vagueness. Cambridge: Cambridge University Press.

Lewis, D. 1982. "Logic for Equivocators." Noûs 16: 431-441.

Lewis, D. 1983. "New Work for a Theory of Universals." Australasian Journal of Philosophy 61: 343-377.

Lewis, D. 1986. On the Plurality of Worlds. Oxford: Basil Blackwell.

Schoenfield, M. 2016. "Moral Vagueness is Ontic Vagueness." Ethics 126: 257-282.

Shafer-Landau, R. 1995. "Vagueness, Borderline Cases and Moral Realism." American Philosophical Quarterly 32: 83-96.

Wedgwood, R. 2001. "Conceptual Role Semantics for Moral Terms." Philosophical Review 110: 1-30.

Williamson, T. 1994. Vagueness. London: Routledge.

Wright, C. 1975. "On the Coherence of Vague Predicates." Synthese 30: 325-365.

Wright, C. 1976. "Language Mastery and the Sorites Paradox." In Truth and Meaning, edited by G. Evans, and J. McDowell, 523-549. Oxford: Oxford University Press. 